\title{
LABOR SUPPLY AND THE DEMAND FOR CHILD CARE: AN INTERTEMPORAL APPROACH
}

\author{
JUNICHI MINAGAWA \\ THORSTEN UPMANN
}

CESIFO WORKING PAPER NO. 1819

CATEGORY 4: LABOUR MARKETS

OCTOBER 2006

An electronic version of the paper may be downloaded

- from the SSRN website:

- from the RePEc website:

- from the CESifo website:

www.SSRN.com

www.RePEc.org

www.CESifo-group.de 


\title{
LABOR SUPPLY AND THE DEMAND FOR CHILD CARE: AN INTERTEMPORAL APPROACH
}

\begin{abstract}
In this paper, we present a model of a one parent-one child household where parental decisions on labor supply, leisure, and the demand for private and public child care are simultaneously endogenized and intertemporally determined. We characterize the path of the optimal decisions and investigate the impact of various public child care fees and of the quality of public child care services on the parent's time allocation and the child's performance level. Our results show that different public child care policies may induce substantially diverging effects, and reveal that each policy frequently faces a trade off between an encouragement of labor supply and an enhancement of the child's performance.
\end{abstract}

JEL Code: D91, H24, H42, J13, J22.

Keywords: child care fees and services, demand for child care, intertemporal optimization, labor supply, leisure, parental time allocation, private and public child care, public child care policy.

\author{
Junichi Minagawa* \\ Graduate School of Economics \\ Chuo University \\ 742-1 Higashi-nakano \\ Hachioji, Tokyo 192-0393 \\ Japan \\ 10111002@crow.grad.tamacc.chuo-u.ac.jp
}

\author{
Thorsten Upmann \\ Institute of Mathematical Economics \\ University of Bielefeld \\ P.O. Box 100131 \\ 33501 Bielefeld \\ Germany \\ TUpmann@wiwi.uni-bielefeld.de
}

September 25, 2006

* Most of this work was done during a visit at the University of Bielefeld in 2005/06. The visit was partially financially supported by the German Academic Exchange Service (DAAD). 


\section{INTRODUCTION}

Considering the political and scientific debates on labor market and family policies, we realize that, with regards to the labor supply side, both policies are closely interweaved: When parents decide as to whether they supply work or not, and, if so, to what extent, they have to make sure that their children are adequately supervised and receive a good education. Hence, the issues of compatibility between labor market participation and labor supply, on the one hand, and of availability of child care services and child education, on the other, cannot be separated. Rather, economists dealing with either side should always take the other side into account as well. - Ideally, an integrated approach treating both sides equally seems to be most desirable.

In the empirical literature the relationship and the interdependencies between family structure, labor supply, and child care demand have already been extensively explored. Pioneering papers on the economics of child care are, for example, Becker and Lewis (1973), Becker and Tomes (1976), and Heckman (1974). The first two papers study the effect of family income on fertility in a quantity-quality model of children, and the last paper analyzes the relationship between labor supply and child care. Subsequent to the study of Heckman, a large number of empirical studies explores the effect of child care cost on labor supply; most of them find this effect to be negative. ${ }^{1}$

While the empirical literature on the relationship between labor supply decisions and child care is vast, only few theoretical papers deal with this issue. Notable contributions are Bergstrom and Blomquist (1996), who discuss public provision of child care services and examine the preferred level of child care subsidies, and Brink and Nordblom (2005), who analyze the effects of various child care subsidies on parental time allocation. Other authors focus on the parents' choice between private and public child care. Examples are Lundholm and Ohlsson (1998), who are concerned with mechanisms similar to those in Bergstrom and Blomquist (1996), and Lundholm and Ohlsson (2002), who generalize the result of Becker and Lewis (1973).

\footnotetext{
${ }^{1}$ See, for example, Averett et al. (1997), Blau and Hagy (1998), Blau and Robins (1988), Connelly (1992), and Ribar (1992). Only a few authors conclude differently. For example, Michalopoulos et al. (1992) and Baum (2002) find the cost effect to be close to zero or positive, respectively.
} 
Even though the few extant theoretical papers represent valuable first steps towards a thorough modeling, they exhibit substantial drawbacks. Most importantly they do not endogenize labor supply, leisure, and child care decisions simultaneously; nor do they investigate this inherently intertemporal issue in a dynamic setting. - We would like to correct for these shortcomings and to fill the gap in the theoretical literature by developing a dynamic model where labor supply, leisure and child care demand are determined endogenously at each instant of time. We apply this framework to scrutinize how the government may interfere with parental labor supply and child care decisions by means of either different fee structures for public child care services or by altering the quality of public child care.

We chose a one parent-one child household approach with an altruistic parent. The single parent-one child model is chosen not because we believe this is the representative family structure, but because it is both an empirically significant family structure and it allows us to capture the most important interdependencies between labor supply and child care decisions without letting the number of endogenous variables increase prohibitively, which would have been the case had we included a second parent and possibly even a second child. The two-person model, though, can be solved without putting too much structure into it, and may thus be viewed as a first step into the direction of a more sophisticated household model. In fact, our approach allows us to characterize the optimal path of the parent's decision variables, and also to investigate the impact of public policies on the parent's behavior at a remarkably general level.

Deriving the parent's utility-maximizing controls, we show that in the course of time, i. e., as the child gets older, parental labor supply and correspondingly the demand for public child care services increases. Yet, an extension of the parent's time horizon, interpreted as a longer education period, decreases both the path of labor supply and of the demand for public child care. Given the behavior of the parent, we then consider various possible public policies. First, the government may levy a fee on public child care, which is either proportional to the parent's income (income-based fee), or proportional to the consumption of public child care (use-based fee), or equals a fixed fee which has to be paid if public child care is used at some instant of time. We demonstrate that these fee systems have quite different effects on labor supply, on the demand for public child care, on leisure time spent with and without the child, and finally, and probably most importantly, on the 
child's performance (or education) level. Thus, the three fee systems are far from being equivalent. In particular, we show that an increase in any of these user fees generally results in opposite effects on labor supply and the child's performance level.

Remarkably, this trade off between labor supply and the child's performance continues to hold even if we consider, as an alternative public policy, a direct enhancement of the quality of public child care services. While an improvement of public child care leads to an increase in parental labor supply and in public child care demand, it decreases the path of the child's performance level - a phenomenon which is at variance with immediate intuition, but can be explained quite well.

We conclude that, given our assumptions, public policy frequently faces a trade off between encouraging labor supply and enhancing the child's educational path. Only for a small use-based fee does this conflict not emerge, and labor market and education targets may be met simultaneously. It is therefore important for policy makers to be aware of the remarkably diverging consequences of different policies. Ignoring these trade offs and the subtle differences of these policies on parental behavior and the child's well-being, a well-meant policy may easily go wrong.

The structure of the paper is as follows. In the next section we set up the parent's intertemporal optimization problem, which we then solve in Section 3. We characterize the path of the optimal leisure, labor supply, and child care decisions and show how these decisions depend on the crucial parameters of the model in Section 4. The impact of different fee systems and of the quality of public child care on the parent's behavior is scrutinized in Section 5. The resulting effect of these policies on the child's performance is then investigated in Section 6. As we shall see, a more rigorous analysis of the use-based fee system is required; this is done in Section 7, where we put more structure in the model. Finally we consider the possibility of corner solutions in Section 8, before we summarize our results in Section 9.

\section{THE ModeL}

We model a parent's decision, who has a child, and must allocate his/her disposable time, which we normalize to unity, to either working, pure leisure (leisure time without the child), or child care activities (leisure time together with the 
child). The instantaneous welfare of the parent depends on consumption, leisure time with and without the child, and on the performance (or well-being) of the child, and is represented by a utility function

$$
F(x(t), l(t), c(t), b(t)):=u(x(t))+v(l(t), c(t))+w(b(t)),
$$

where $x(t)$ denotes consumption of some unspecified aggregate consumption bundle in period $t, l(t)$ represents the amount of leisure time spent without the child, $c(t)$ is the leisure time spent with the child (or parental child care), and $b(t)$ represents the child's well-being, education level, or performance. With respect to the subutility functions $u, v$, and $w$ we assume the following.

(i) $u: \mathbb{R}_{+} \rightarrow \mathbb{R}$ is continuous, $u^{\prime}$ and $u^{\prime \prime}$ exist on $\mathbb{R}_{++}, u^{\prime}>0, u^{\prime \prime}<0$, and $u^{\prime}(x) \rightarrow \infty$ as $x \rightarrow 0^{+}$.

(ii) $v: \mathbb{I}^{2} \rightarrow \mathbb{R}$ is continuous, $v_{l}, v_{c}, v_{l l}, v_{l c}$, and $v_{c c}$ exist on $\stackrel{\circ}{\mathbb{I}^{2}}, v_{l}>0, v_{c}>0$, $v_{l l}<0, v_{c c}<0, v_{l l} v_{c c}-\left(v_{l c}\right)^{2}>0, v_{l}(l, c) \rightarrow \infty$ as $l \rightarrow 0^{+}, v_{c}(l, c) \rightarrow \infty$ as $c \rightarrow 0^{+}$, and for some sufficiently small positive constant $n_{1}: v_{l c}>-n_{1}$, that is, $v_{l c}$ is bounded from below.

(iii) $w: \mathbb{R}_{+} \rightarrow \mathbb{R}$ is continuous, $w^{\prime}$ and $w^{\prime \prime}$ exist on $\mathbb{R}_{++}, w^{\prime}>0$, and $w^{\prime \prime}<0$.

We use the following notation throughout the paper: $\mathbb{R}_{+} \equiv[0, \infty) ; \mathbb{R}_{++} \equiv(0, \infty)$; $\mathbb{I} \equiv[0,1] ; \stackrel{\circ}{\mathbb{I}} \equiv(0,1) ;$ a prime means differentiation; a subscript denotes the variable with respect to which the partial derivative is taken.

We treat the child's performance $b(t)$ as a stock variable to which both parental and public child care contribute. Thus, the pure process of growing up, $\dot{b}(t)=g(b(t)), b(0)=b^{0}>0$, may be enhanced by instantaneous child care activities. We assume that parental child care, measured in efficiency units, is equal to the leisure time spent together with the child, $c(t)$, while public child care consumption, measured in efficiency units, is proportional to the amount of public child care consumption (measured in hours), $d(t)$, and is thus given by $y(t) \equiv q d(t)$. Here the productivity parameter $q>0$ represents the quality (or intensity) of public child care. This formulation allows us to investigate the impact of, say, a higher kindergarten or school quality on the parent's leisure and labor supply decisions.

Altogether, the compound effect of both private and public child care (measured in efficiency units) on the rate at which a child's education or, more broadly, its performance is enhanced, may be characterized by a production function $f$ : $\mathbb{I} \times \mathbb{R}_{+} \rightarrow \mathbb{R}:(c, y) \mapsto f(c, y)$, and the evolution of $b(t)$ is, thus, governed by the 
differential equation

$$
\dot{b}(t)=f(c(t), y(t)) g(b(t)) .
$$

Note that according to this specification parental and public child care are imperfect substitutes in the educational production function. This represents a substantial generalization of the simple linear technology, where (child) quality is proportional to the sum of parental and public child care (measured in hours), predominantly used in the literature (see, for example, Lundholm and Ohlsson (2002)). With regard to the production functions $f$ and $g$, we assume the following.

(iv) $f: \mathbb{I} \times \mathbb{R}_{+} \rightarrow \mathbb{R}$ is continuous, $f_{c}, f_{y}, f_{c c}, f_{c y}$, and $f_{y y}$ exist on $\stackrel{\circ}{\mathbb{I}} \times \mathbb{R}_{++}$, $f(0,0) \leqslant 1, f_{c}>0, f_{y}>0, f_{c c} \leqslant 0, f_{y y} \leqslant 0, f_{c c} f_{y y}-f_{c y} \geqslant 0$, and, for some sufficiently small positive constant $n_{2}, f_{c y}>-n_{2}$, that is, $f_{c y}$ is bounded from below.

(v) $g: \mathbb{R}_{+} \rightarrow \mathbb{R}_{+}$is continuous, $g^{\prime}$ and $g^{\prime \prime}$ exist on $\mathbb{R}_{++}, g(0)=0, g^{\prime}>0$, and $g^{\prime \prime} \leqslant 0$.

Since the parent may devote his/her disposable time to either working, pure leisure, or child care, labor supply is endogenized. For simplicity we assume that at any point in time the parent may find a job suitable to meet his/her labor supply decision, $h(t):=1-l(t)-c(t) \in \mathbb{I}$, at the actual (real) wage rate $\omega>0$. Thus, the parent's time constraint reads as

$$
h(t)+l(t)+c(t)=1
$$

and the total time of child care must be equal to the amount of disposable time:

$$
c(t)+d(t)=1
$$

At each instant of time, total expenditure on consumption and public child care must meet labor income. Normalizing the price of the consumption bundle to unity, the instantaneous budget constraint of the parent is given by

$$
x(t)+\phi(d(t), M(t))=\omega h(t) \equiv M(t),
$$

where $\phi: \mathbb{I} \times \mathbb{R}_{+} \rightarrow \mathbb{R}:(d, M) \mapsto \phi(d, M)$ represents the public child care fee which may, in principle, depend on both the consumption of public child care and the parent's income, $M(t)$. To be more specific, we assume the following fee structure. 
(vi) $\phi: \mathbb{I} \times \mathbb{R}_{+} \rightarrow \mathbb{R}_{+}$is defined by $\phi(d(t), M(t)):=\alpha M(t) \mathbf{1}_{d(t)>0}+\beta d(t)+$ $\gamma \mathbf{1}_{d(t)>0}, 1>\alpha \geqslant 0, \beta \geqslant 0$, and $\gamma \geqslant 0$,

where $\mathbf{1}_{A}$ represents the indicator function, yielding 1 if $A$ is true and 0 otherwise. The parameters $\alpha, \beta$, and $\gamma$ are regarded as the income 'tax rate', the price for public child care (per unit of time), and a fixed user fee for public child care, respectively. In what follows, we discuss the following (pure) fee structures

$$
\begin{array}{lll}
\text { income-based fee: } & \phi^{\alpha}(d(t), M(t) ; \alpha) & :=\alpha M(t) \mathbf{1}_{d(t)>0}, \\
\text { use-based fee: } & \phi^{\beta}(d(t) ; \beta) & :=\beta d(t), \\
\text { flat fee: } & \phi^{\gamma}(d(t) ; \gamma) & :=\gamma \mathbf{1}_{d(t)>0} .
\end{array}
$$

(These fee schemes have also been studied by Brink and Nordblom (2005), though in a static framework.)

Let $T$ denote the fixed time horizon, which may be interpreted as the age at which the child no longer requires child care. Finally, we assume that the present value of the child's performance at the fixed end of the child care period is given by $\psi(b(T)):=\epsilon w(b(T)) e^{-r T}$. Here $\epsilon>0$ is the weight parameter and $r>0$ is the discount rate. The intertemporal problem of the parent is then as follows:

$$
\begin{array}{cl}
\max _{\{x(t), l(t), c(t), d(t), h(t)\}} & \int_{0}^{T}[u(x(t))+v(l(t), c(t))+w(b(t))] e^{-r t} d t+\epsilon w(b(T)) e^{-r T}, \\
\text { s.t. } & \dot{b}(t)=f(c(t), y(t)) g(b(t)), \\
& y(t)=q d(t), \\
& h(t)+l(t)+c(t)=1, \\
& c(t)+d(t)=1, \\
& x(t)+\alpha M(t) \mathbf{1}_{d(t)>0}+\beta d(t)+\gamma \mathbf{1}_{d(t)>0}=M(t), \\
& M(t)=\omega h(t), \\
& (x(t), l(t), c(t), d(t), h(t)) \in \mathbb{R}_{+} \times \mathbb{I}^{4}, \\
& b(0)=b^{0}>0, b^{0} \text { fixed }, \\
& b(T) \geqslant 0,
\end{array}
$$

$T$ fixed.

The parent maximizes his/her intertemporal (altruistic) utility with respect to consumption, pure leisure time, private child care, public child care, and labor supply subject to the motion of the child's education level, the time constraints, the budget constraint, and the boundary constraints. 


\section{Intertemporal Child Care Demand and Labor Supply}

In this section, we solve the parent's problem. First, to make the problem more tractable, we reduce the dimension of the problem by using the constraints (3)-(5) together with (vi). This allows us to eliminate the controls $c, l$, and $x$, and the problem reduces to (omitting the time variable):

$$
\begin{aligned}
\max _{\{d, h\}} & \int_{0}^{T}\left[u\left(\omega^{\alpha} h-\beta d-\gamma \mathbf{1}_{d>0}\right)+v(d-h, 1-d)+w(b)\right] e^{-r t} d t+\epsilon w(b(T)) e^{-r T}, \\
\text { s.t. } & \dot{b}=f(1-d, q d) g(b) \\
& 1 \geqslant d \geqslant 0, \quad d \geqslant h, \quad h \geqslant\left(\beta d+\gamma \mathbf{1}_{d>0}\right) / \omega^{\alpha} \\
& b(0)=b^{0}>0, b^{0} \text { fixed, } \\
& b(T) \geqslant 0 \\
& T \text { fixed, }
\end{aligned}
$$

where $\omega^{\alpha} \equiv\left(1-\alpha \mathbf{1}_{d>0}\right) \omega>0$ is the after-tax real wage rate. In order for constraint (8) to be meaningful, we assume $\omega^{\alpha}>\beta+\gamma$.

In this problem, the Hamiltonian, $H$, given below, is not necessarily concave in $(b, d, h)$, implying that $H$ does not to satisfy the Mangasarian-type sufficiency condition (see, e.g., Seierstad and Sydsæter (1987)) frequently used in the literature. In order to solve the problem, though, we proceed with the following steps. We provide a condition under which the maximum principle yields a unique candidate for optimality. We then show that the conditions of the Filippov-Cesari existence theorem are satisfied, thereby establishing the existence of an optimal triple $\left(b^{*}(t), d^{*}(t), h^{*}(t)\right)$. We therefore conclude that the unique candidate produced by the maximum principle is indeed optimal. These results are shown in Appendix A. Eventually we arrive at the following proposition.

Proposition 1. Consider the problem (6)-(11) together with Assumptions (i)-(v) and $\omega^{\alpha}>\beta+\gamma$. If $w^{\prime}(b) g(b)=C, C$ a positive constant, then there exists a unique optimal triple $\left(b^{*}(t), d^{*}(t), h^{*}(t)\right)$ such that $b^{*}(t)>0,1>d^{*}(t)>0, d^{*}(t)>h^{*}(t)$, and $h^{*}(t)>\left(\beta d^{*}(t)+\gamma\right) / \omega^{\alpha}$ for all $t \in[0, T]$.

Proof. See Appendix A. 
The assumption, $w^{\prime}(b) g(b)=C$, simplifies the proof that the maximum principle provides a unique candidate for optimality. ${ }^{2}$ On the other hand, however, it is also reasonable from an economic point of view, for it seems that, the lower the child's productivity (or ability) of self-development is, the more marginal utility the parent derives from an improvement of the child's performance.

\section{Inspection of the Optimal Solution}

We shall now investigate the properties of the optimal solution. This is done in Propositions 2 and 3 which characterize the optimal path and the dependence of the optimal solution on the time horizon, the discount rate, and the weight of the child's final performance level at the end of the child care period.

Proposition 2. Consider the optimal triple of Proposition 1. The optimal control $\left(d^{*}(t), h^{*}(t), c^{*}(t), l^{*}(t)\right)$ has the following characteristics on times, $t$ and $T$ :
(A) $(r \epsilon-1)\left(f_{c}-q f_{y}\right) \gtreqless 0 \Leftrightarrow \dot{d}^{*} \lesseqgtr 0 \Leftrightarrow \dot{h}^{*} \lesseqgtr 0 \Leftrightarrow \dot{c}^{*} \gtreqless 0 \Leftrightarrow\left\{i^{*} \lesseqgtr 0\right.$, given $\left.v_{l c}=0\right\}$,
(B) $(r \epsilon-1)\left(f_{c}-q f_{y}\right) \gtreqless 0 \Leftrightarrow d_{T}^{*} \gtreqless 0 \Leftrightarrow h_{T}^{*} \gtreqless 0 \Leftrightarrow c_{T}^{*} \lesseqgtr 0 \Leftrightarrow\left\{l_{T}^{*} \gtreqless 0\right.$, given $\left.v_{l c}=0\right\}$,

where $f_{c}, f_{y}$, and $v_{l c}$ are evaluated along the optimal path.

Proof. See Appendix B.

Most importantly, the time path of the demand for public child care and labor supply hinges, beyond its dependence on the discount rate and the weight of the child's ultimate achievement level, on the productivity gap between private and public child care, $f_{c}-q f_{y}$. Assume that the productivity of private child care exceeds the productivity of public child care, and that the discount rate is moderate, such that $r \epsilon<1$. Then the demand for public child care and labor supply are initially low and increase in the course of time, i. e., as the child grows up. Correspondingly, leisure time spent together with the child decreases over time, while the effect on leisure time spent without the child is unclear in general. Yet, for the special case when utility is separable between leisure time spent with and without the child, $v_{l c}=0$, leisure time without the child is increasing over time. This feature is consistent with common real-world observations: When a child is born, labor supply frequently drops and the parent spends much of his/her

\footnotetext{
${ }^{2}$ This type of assumption and an example of a pair of functions satisfying the assumption, provided in Section 6, have been presented by Xie (1991, 1997), though in different settings.
} 
time together with the child. As it grows up, the child is sent to kindergarten first and to school later, implying that the amount of public child care increases while the amount of private child care decreases over time. With more time left at his/her discretion, the parent tends to increase labor supply and plausibly also to spend more leisure time without the child.

Similarly, if the length of the education period is increased, labor supply and the demand for public child care fall (under the assumption $(r \epsilon-1)\left(f_{c}-q f_{y}\right)<0$ ), implying an increase in leisure time spent together with the child and plausibly a reduction in the leisure time spent without the child. The intuition is as follows. With an extended education period the parent derives utility from the child's performance over a longer period of time, making (early) investment in the child's well-being more valuable. Thus, given that the productivity of private child care exceeds that of public child care, the parent is willing to spend more leisure time together with the child. - Interpreting $T$ as the end of schooltime, we may conclude that an increase in required total schooltime lowers the parent's labor supply but makes him/her spend more time together with the child at each instant during the education period. Viewed from another perspective, suppose a parent knew that his/her child will eventually visit high school (and thus $T$ is large), the parent would arguably invest a higher amount of time in educational activities as compared to a child which is sure to leave school immediately at the end of compulsory education.

Proposition 3. Consider the optimal triple of Proposition 1. The optimal control $\left(d^{*}(t), h^{*}(t), c^{*}(t), l^{*}(t)\right)$ has the following characteristics on the discount factor, $r$, and the weight of the child's final education level, $\epsilon$ :

(A) $f_{c}-q f_{y} \gtreqless 0 \Leftrightarrow d_{r}^{*} \gtreqless 0 \Leftrightarrow h_{r}^{*} \gtreqless 0 \Leftrightarrow c_{r}^{*} \lesseqgtr 0 \Leftrightarrow\left\{l_{r}^{*} \gtreqless 0\right.$, given $\left.v_{l c}=0\right\}$,

(B) $f_{c}-q f_{y} \gtreqless 0 \Leftrightarrow d_{\epsilon}^{*} \lesseqgtr 0 \Leftrightarrow h_{\epsilon}^{*} \lesseqgtr 0 \Leftrightarrow c_{\epsilon}^{*} \gtreqless 0 \Leftrightarrow\left\{l_{\epsilon}^{*} \lesseqgtr 0\right.$, given $\left.v_{l c}=0\right\}$,

where $f_{c}, f_{y}$, and $v_{l c}$ are evaluated along the optimal path.

Proof. See Appendix B.

In order to interpret this result, we begin with the effect of a higher weight of the child's ultimate performance level in the parent's intertemporal utility function. Assume again, that the productivity of private child care exceeds the productivity of public child care, $f_{c}-q f_{y}>0$. With a higher value of $\epsilon$ the parent puts more value on the child's education performance at the end of the education period. With a higher productivity of private child care, when compared with public child 
care, the opportunity cost of public child care, measured in forgone performance of the child, increases with $\epsilon$. This makes the parent spend more time together with the child and reduce his/her leisure time without the child; at the same time he/she reduces the demand for public child care and cuts labor supply. In this respect the effect of an increase in $\epsilon$ is comparable with an extension of the education period (increase in $T$ ). In both cases the parent becomes more concerned about the child's well-being resulting in a substitution away from all activities towards leisure time spent together with the child.

The reverse argument applies when the discount rate increases. A higher discount rate makes the present more valuable, when compared with the future. Since the benefits from education are (mainly) attributed to the future, while the benefit from consumption and pure leisure time is immediate, the parent substitutes private by public child care in order to be able to increase both leisure time without the child and labor supply. In this sense a more impatient (or more myopic) parent devotes less effort in educational activities than a more patient (or forward-looking) parent. Thus, the comparative static effect of a parent becoming more patient or more forward-looking (a decrease in $r$ ) is equivalent to the parent becoming more concerned about the well-being of the child (an increase in $\epsilon$ ).

\section{Public Fee and Service Policies}

Since we are not only interested in the optimal behavior of the parent, but also and arguably more importantly, in the dependence of the optimal solution on policy parameters, we seek to characterize the impact of public policy on child care and labor market participation decisions in this section. In this way we reveal some scope for an improvement of both family and labor market policies. In this respect Proposition 4 provides a central result, as it shows the impact of different user-fee systems and of the efficiency of public child care on the demand for private and public child care, pure leisure time, and labor supply. - To formalize these results, we subsequently write $\hat{f}(d, q)$ instead of $\hat{f}(d):=f(1-d, q d)$ and $\hat{f}_{d q}=f_{y}+y f_{y y}-d f_{c y}$ for the corresponding cross derivative.

Proposition 4. Consider the optimal triple of Proposition 1. The optimal control $\left(d^{*}(t), h^{*}(t), c^{*}(t), l^{*}(t)\right)$ has the following characteristics on policy parameters, $\alpha$, $\beta, \gamma$, and $q$ :
(A) If $\phi:=\phi^{\alpha}$, then $-x^{*} u^{\prime \prime} / u^{\prime} \gtreqless 1 \Leftrightarrow d_{\alpha}^{*} \gtreqless 0 \Leftrightarrow h_{\alpha}^{*} \gtreqless 0 \Leftrightarrow c_{\alpha}^{*} \lesseqgtr 0 \Leftrightarrow l_{\alpha}^{*} \lesseqgtr 0$,
(B) If $\phi:=\phi^{\beta}$, then the signs of $d_{\beta}^{*}, h_{\beta}^{*}, c_{\beta}^{*}$, and $l_{\beta}^{*}$ are not clear, 
(C) If $\phi:=\phi^{\gamma}$, then $d_{\gamma}^{*}>0, h_{\gamma}^{*}>0, c_{\gamma}^{*}<0$, and $l_{\gamma}^{*}<0$,

(D) $\hat{f}_{d q} \gtreqless 0 \Leftrightarrow d_{q}^{*} \gtreqless 0 \Leftrightarrow h_{q}^{*} \gtreqless 0 \Leftrightarrow c_{q}^{*} \lesseqgtr 0 \Leftrightarrow\left\{l_{q}^{*} \gtreqless 0\right.$, given $\left.v_{l c}=0\right\}$,

where $u^{\prime}, u^{\prime \prime}, \hat{f}_{d q}$, and $v_{l c}$ are evaluated along the optimal path.

Proof. See Appendix C.

Proposition 4 illustrates how the government may interfere with the parent's child care and labor market decisions by changing either the fees levied on income and on the use of public child care or by changing the quality of public child care services. If public child care is financed by an income-based fee, $\phi=\phi^{\alpha}$, a higher fee (or tax), $\alpha$, decreases labor supply and the demand for public child care, provided that the elasticity of the marginal utility of consumption, $-x^{*} u^{\prime \prime} / u^{\prime}$, is not too large; and it correspondingly increases leisure time both with and without the child. Only if this elasticity exceeds unity (in absolute terms) does the parent increase his/her labor supply and thus the demand for public child care. In this case, the parent is not willing to let his/her consumption level fall by too large an amount and is therefore forced to extend working hours in order to compensate for higher fees.

If, however, public child care is financed by a use-based fee, $\beta$, to be paid for each hour the child has been in public care, the effect of an increase in $\beta$ has no clear effect on either labor supply or child care demand. In order to obtain some comparative results, we are required to put more structure on the sub-utility functions $u$ and $v$ and the production function $f$. This is done in Section 7 .

The third alternative to finance the provision of public child care is a fixed premium, $\gamma$, which has to be paid if, and only if, the child has been in public care. As long as the parent is willing to work and is thus constrained to use at least some amount of public child care, this premium acts like a poll tax for the parent. In order to mitigate the resulting income loss, the parent increases labor supply and thus the demand for public child care, as $\gamma$ increases. Correspondingly, both leisure time spent with and without the child fall.

Finally, the effect of an improvement of public child care quality depends on whether the quality and the amount of public child care are complements or substitutes in the (derived) production process of education. If both are complements, i. e., if the marginal product of an hour shifted from private to public child care increases with the efficiency of public child care, $\hat{f}_{d q}>0$, which we believe to be 
the more plausible case ${ }^{3}$ an enhanced efficiency of public child care makes the parent substitute private by public care, enabling him/her to work more. The effect on leisure time spent without the child is unclear in general, but at least if $v$ is separable, pure leisure time increases. The intuition for this result is as follows. With a higher quality of public child care the necessity to complement public child care by private child care decreases. For this reason the parent is more inclined to let the child be supervised publicly. In this way the parent has more time at his/her discretion, part of which is used for working, part of which is used for leisure time without the child.

\section{Effects on the Child's Performance}

In the preceding sections we have characterized the optimal solution and provided the corresponding comparative static results for the controls $d, h, c$, and $l$, collected in Propositions 2-4. These results have been obtained under quite general conditions, the only restriction we imposed, beyond the usual concavity conditions (i)-(v), is the product of $w^{\prime}$ and $g$ to be constant. Comparative static results for the optimal path of the state variable $b$ are, however, more difficult to obtain. For this reason, we subsequently specify $w$ and $g$ in such a way that, as previously assumed, $w^{\prime}(b) g(b)$ is constant for any $b$. This may be accomplished by the following specification:

$$
w(b):=\frac{b^{1-\sigma}-1}{1-\sigma}, \quad \text { and } \quad g(b):=A b^{\sigma},
$$

where $\sigma \in(0,1)$ and $A>0$. (Note that $w(b)$ converges to $\ln (b)$ for $\sigma \rightarrow 1$.) With this specification we obtain $w^{\prime}(b) g(b)=A$, and therefore, a unique optimal triple exists, due to Proposition 1.

Proposition 5. Consider the optimal triple of Proposition 1, and let $w$ and $g$ be specified as in eq. (12). The optimal state $b^{*}(t)$ has the following characteristics on the discount factor, $r$, and the weight of the child's final education level, $\epsilon$ :

(A) $f_{c}-q f_{y} \gtreqless 0 \Rightarrow b_{r}^{*} \lesseqgtr 0$,

(B) $f_{c}-q f_{y} \gtreqless 0 \Rightarrow b_{\epsilon}^{*} \gtreqless 0$,

\footnotetext{
${ }^{3}$ As we infer from the relationship $\hat{f}_{d q}=f_{y}+y f_{y y}-d f_{c y}$ there are quite a few conditions that guarantee $\hat{f}_{d q}>0$. For example, if (a) $f$ is separable, $f_{c y}=0$, and 'not too concave' in $y$, in the sense that $f_{y}+y f_{y y}>0$ or if (b) private and public child care are (weak) substitutes $f_{c y} \leqslant 0$ and $f$ is linear in $y$, we obtain $\hat{f}_{d q}>0$. In our subsequent examples we use $f(c, y):=c+y$ which implies $\hat{f}_{d q}=1$.
} 
where $f_{c}$ and $f_{y}$ are evaluated along the optimal path.

Proof. See Appendix D.

If private child care activity is more effective in achieving a higher performance level of the child than is public child care, $f_{c}-q f_{y}>0$, an increase in the discount rate, $r$, shifts the optimal path of child's performance downwards. In view of Proposition 3 this is exactly what we expect, for a higher discount rate lets the parent work more and spend less time together with the child. Moreover, as we have already seen in the sequence of Proposition 3, the effect of a higher value of the child's ultimate achievement level, $\epsilon$, is just opposite to that of a higher discount rate. Hence, with more time spent together with the child, its performance will improve, given that $f_{c}-q f_{y}>0$.

With the specification of $w$ and $g$ as given in eq. (12), we are also able to characterize the impact of fee policies on the optimal path of the child's performance, except for the use-based fee $\phi=\phi^{\beta}$.

Proposition 6. Consider the optimal triple of Proposition 1, and let $w$ and $g$ be specified as in eq. (12). The optimal state $b^{*}(t)$ has the following characteristics on policy parameters, $\alpha, \beta, \gamma$, and $q$ :

(A) If $\phi:=\phi^{\alpha}$, then $\left(-x^{*} u^{\prime \prime} / u^{\prime}-1\right)\left(f_{c}-q f_{y}\right) \gtreqless 0 \Rightarrow b_{\alpha}^{*} \lesseqgtr 0$,

(B) If $\phi:=\phi^{\beta}$, then the sign of $b_{\beta}^{*}$ is not clear,

(C) If $\phi:=\phi^{\gamma}$, then $f_{c}-q f_{y} \gtreqless 0 \Rightarrow b_{\gamma}^{*} \lesseqgtr 0$,

(D) $\hat{f}_{d q}\left(f_{c}-q f_{y}\right) \gtreqless 0 \Rightarrow b_{q}^{*} \lesseqgtr 0$,

where $u^{\prime}, u^{\prime \prime}, f_{c}, f_{y}$, and $\hat{f}_{d q}$ are evaluated along the optimal path.

Proof. See Appendix D.

Under an income-based fee, $\phi=\phi^{\alpha}$, a higher fee (or tax), $\alpha$, shifts the optimal path of the child's achievement level upwards, provided that the elasticity of the marginal utility of consumption, $-x^{*} u^{\prime \prime} / u^{\prime}$, is not too large and that private child care is more productive than public child care, $f_{c}-q f_{y}>0$. This merely reflects our previous findings, see Proposition 4(A), that a higher fee reduces the opportunity cost of leisure time, inducing the parent to work less and to reduce the demand for public child care, but to spend more time engaging in leisure activities - both, with and without the child. Clearly, such behavior of the parent must be beneficial for the child and thus shifts the optimal path of $b$ upwards. 
In case of a use-based fee system, $\phi=\phi^{\beta}$, little can be said about the effect of an increase in the fee $\beta$ on the path of the child's performance level. Therefore, we postpone a discussion until specifications of $u, v$, and $f$ allow us to draw some conclusions.

As previously seen, the marginal effects of a flat fee, $\gamma$, on the optimal controls and thus on the path of the state variable are basically opposite to those obtained under an income-based fee. We know from Proposition 4(C) that a higher fixed fee for public child care acts as a poll tax for the parent, who seeks to compensate the induced income loss by an increase in labor supply. The resulting fall in leisure time spent together with the child then leads to a lower path of the child's performance level.

Finally, the effect of an improvement of the quality of public child care, $q$, is comparable with that of a higher fixed fee, $\gamma$, provided that public child care ( $d$ measured in hours) and its quality (measured by $q$ ) are complements in the (derived) education process, i. e., $\hat{f}_{d q}>0$. With a higher quality of public child care the parent is willing to increase both labor supply and the demand for public child care (cf. Proposition 4(D)). The child's performance level, however, falls with less parental child care due to an assumed lower productivity of public child care, $f_{c}-q f_{y}>0$.

\section{The Use-Based Fee System: An Example}

The only comparative static effect which is unclear so far is the impact of the user fee $\beta$ in a use-based fee system on the optimal controls and the state variable. In order to obtain some concrete result, it is useful to specify the utility functions $u$ and $v$ and the education function $f$. In Example 1 we consider a possible setting which allows for explicit solutions of the control variables.

Example 1. Let

$$
u(x):=\frac{x^{1-\tau}-1}{1-\tau}, \quad v(l, c):=\frac{l^{1-\tau}-1}{1-\tau}+\frac{c^{1-\tau}-1}{1-\tau}, \quad f(c, y):=c+y,
$$

where $\tau \in(0,1)$, satisfying Assumptions (i), (ii), and (iv), and let $q=1$. Then $f_{c}-q f_{y}=0$. From Propositions 2 and 3, the unique optimal control depends on the parameters, $\alpha, \beta, \gamma, \tau$, and $\omega$.

Proposition 7. Consider the optimal triple of Proposition 5, together with the specification as given in (13). Let $q=1$. Then 
(A) If $\phi:=\phi^{\beta}$, then $d_{\beta}^{*}<0, c_{\beta}^{*}>0$, and $l_{\beta}^{*}<0$; also $h_{\beta}^{*} \gtreqless 0 \Leftrightarrow\left(\omega^{1 / \tau}+(\omega-\right.$ $\left.\beta)^{1 / \tau}\right)\left(\omega+\omega^{1 / \tau}\right) \tau-\omega^{1 / \tau}\left(\omega^{1 / \tau}+\beta\right) \gtreqless 0$.

(B) If $\phi:=\phi^{\beta}$, then $b_{\beta}^{*}=0$.

Proof. See Appendix E.

In a use-based system, a higher fee, $\beta$, decreases the demand for public child care and for leisure time spent without the child, but increases the leisure time spent together with the child. In order to investigate the effect on labor supply, we set $\Delta(\beta):=\left(\omega^{1 / \tau}+(\omega-\beta)^{1 / \tau}\right)\left(\omega+\omega^{1 / \tau}\right) \tau-\omega^{1 / \tau}\left(\omega^{1 / \tau}+\beta\right)$. Then, we have $\Delta^{\prime}<0, \Delta(0)=\omega^{2 / \tau}\left(2\left(\omega^{1-1 / \tau}+1\right) \tau-1\right)$ which is positive, at least, for $\tau>1 / 2$, and $\Delta \rightarrow-\left(\omega+\omega^{1 / \tau}\right) \omega^{1 / \tau}(1-\tau)<0$ as $\beta \rightarrow \omega$. Therefore, if public child care is financed by a use-based fee, $\beta$, the effect of an increase in this fee on labor supply is not monotonic, that is, it is positive for low fees but negative for high fees, provided that the elasticity of the marginal utility of consumption (and also of leisure with and without the child) is not too small. Intuitively, in order to compensate for a higher use-based fee, the parent works more as long as the fee does not exceed the threshold $\bar{\beta}$ defined by $\Delta(\bar{\beta})=0$; for a fee exceeding this threshold, though, he/she spends more time with the child and reduces his/her labor supply. This leads to a lower demand for public child care along with a lower amount of leisure time spent without the child.

The impact of the fee $\beta$ on the optimal path of the child's performance level is unclear for an arbitrary level of $q$. Nevertheless, due to the continuity of the optimal path of the demand for public child care on the quality, we know from Part (A) that for $q$ sufficiently close to unity, we have $d_{\beta}^{*}<0$. Together with the assertion in the proof of Part (B), $b_{\beta}^{*} \gtreqless 0$ if $-\left(f_{c}-q f_{y}\right) d_{\beta}^{*} \gtreqless 0$, we therefore obtain $1-q \gtreqless 0 \Rightarrow b_{\beta}^{*} \gtreqless 0$, for all $q$ sufficiently close to unity. In this case, under a user-fee system, $\phi=\phi^{\beta}$, a higher fee, $\beta$, shifts the optimal path of the child's performance upwards, provided that the efficiency of private child care (which we normalized to unity) exceeds that of public child care, i. e., $1>q$. This result is a direct consequence of the decrease in the demand for public child care, which implies an increase in leisure time spent together with the child. Thus, the effect of a higher use-based fee is, apart from the effect on $l$, comparable with the effect of a higher income-based fee (or tax rate). (See Proposition 6(A). Note that, in this example, the elasticity of the marginal utility of consumption falls short of unity, for $-x^{*} u^{\prime \prime} / u^{\prime}=\tau<1$.) 
For the specification given in eq. (13) we illustrate the behavior of the optimal controls under all three fee systems in Figure 1. Here, we set $\omega=1$ and $\tau=1 / 2$.
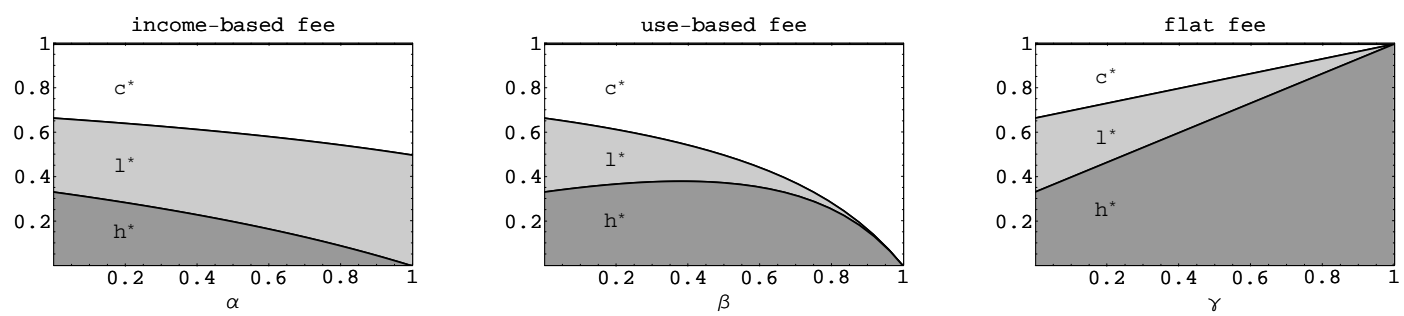

FiguRE 1. Interior optimal control over the fee parameter.

\section{Relaxing Assumptions: Allowing for Corner Solutions}

The assumption, $v_{l}(l, c) \rightarrow \infty$ as $l \rightarrow 0^{+}$, which excludes $l=0(d=h)$ being optimal, seems to be more restrictive than the other two assumptions, $u^{\prime}(x) \rightarrow \infty$ as $x \rightarrow 0^{+}$and $v_{c}(l, c) \rightarrow \infty$ as $c \rightarrow 0^{+}$, since in the real world we find parents who have little or no leisure time without the child. We therefore relax the first assumption by considering the case $v_{l}(l, c) \rightarrow n_{3}<\infty$ as $l \rightarrow 0^{+}$. This may be accomplished by the following generalization of Example 1.

Example 2. We assume the same setting as in Example 1 except that we put $v(l, c):=\left((l+p)^{1-\tau}-1\right) /(1-\tau)+\left(c^{1-\tau}-1\right) /(1-\tau)$ where $p$ is a positive constant. Note that Example 1 is recovered as the limiting case when $p$ approaches 0 . To recapitulate, we apply the following specification:

$$
u(x):=\frac{x^{1-\tau}-1}{1-\tau}, \quad v(l, c):=\frac{(l+p)^{1-\tau}-1}{1-\tau}+\frac{c^{1-\tau}-1}{1-\tau}, \quad f(c, y):=c+y,
$$

where $p>0$, and let $q=1$. Note that this specification satisfies Assumptions (i) and (iv) but not Assumption (ii).

Proposition 8. Consider the problem (6)-(11), together with the specification as given in (12) and $\left(13^{\prime}\right)$. Let $q=1$. Then

(A) If $\phi:=\phi^{\alpha}$, then $l^{*} \in(0,1)$ or $l^{*}=0$. Moreover, 1$), l_{p}^{*}<0$ when $l^{*} \in(0,1)$, and 2), for all $\omega$ there exists some $m_{1}(p) \in[0,1)$ such that $l^{*}=0$ for all $\alpha \leqslant m_{1}(p)$.

(B) If $\phi:=\phi^{\beta}$, then $l^{*} \in(0,1)$ or $l^{*}=0$. Moreover, 1$), l_{p}^{*}<0$ when $l^{*} \in(0,1)$, and 2), for all $\omega$ there exists some $m_{2}(p) \in[0, \omega)$ such that $l^{*}=0$ for all $\beta \geqslant m_{2}(p)$. 
(C) If $\phi:=\phi^{\gamma}$, then $l^{*} \in(0,1)$ or $l^{*}=0$. Moreover, 1$), l_{p}^{*}<0$ when $l^{*} \in(0,1)$, and 2), for all $\omega$ there exists some $m_{3}(p) \in[0, \omega)$ such that $l^{*}=0$ for all $\gamma \geqslant m_{3}(p)$.

Proof. See Appendix F.

The first parts are intuitive since $l$ and $p$ are perfect substitutes. A higher value of the parameter $p$ reduces the marginal utility of leisure time without the child, inducing the parent to spend less time for leisure activities without the child, regardless of the fee structure. The second parts illustrate how the mode of financing the provision of public child care affects the possibility of zero demand for leisure time without the child. Notably the effect of an income-based fee (or tax rate) is opposite to those of a use-based fee and a flat fee. With a lower income-based fee the opportunity cost of leisure time increases and the parent is willing to work more. If the value of $p$ is sufficiently high, leisure time without the child eventually reaches zero. The same happens if either the use-based fee $\beta$ or the flat fee $\gamma$ increases. In both cases, a negative income effect makes the parent reduce leisure time spent without the child. This feature is exactly what we expect from our previous findings for $p=0, l_{\alpha}^{*}>0, l_{\beta}^{*}<0$, and $l_{\gamma}^{*}<0$ (see Propositions 4(A), 7(A), and 4(C), respectively).

For the specification given in eq. $\left(13^{\prime}\right)$ we illustrate the dependencies of the optimal controls on changes of the fee structure and on the value of $p$ in Figure 2 . Here, we again set $\omega=1$ and $\tau=1 / 2$.

\section{Conclusion}

There is a vast empirical literature on parental labor supply and child care decisions, but at the same time, very few papers tackle this issue from a theoretical point of view. Yet, since labor market participation as well as education and child care decisions are central to labor market and family policies, this issue is too important to be neglected and not to receive a thorough theoretical analysis. In this paper we therefore seek to fill this gap and set up a model of a one parentone child household, for which we solve the optimal leisure, labor supply and child care problem. In this way, labor market participation and child care demand are simultaneously endogenized and intertemporally determined. 

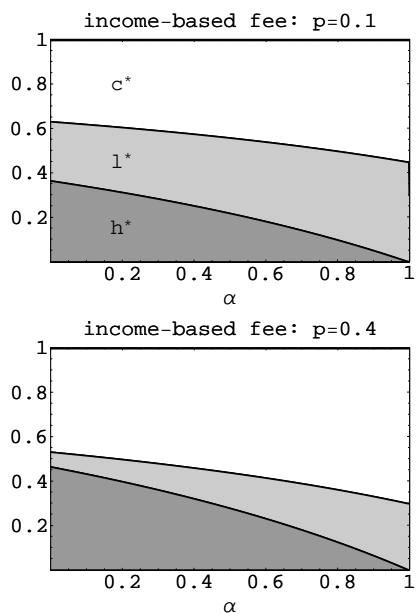

income-based fee: $p=0.7$

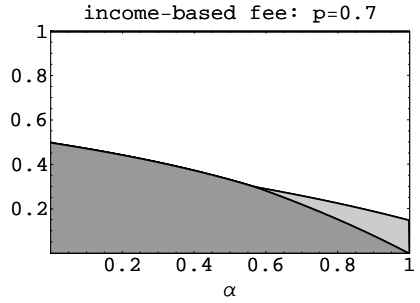

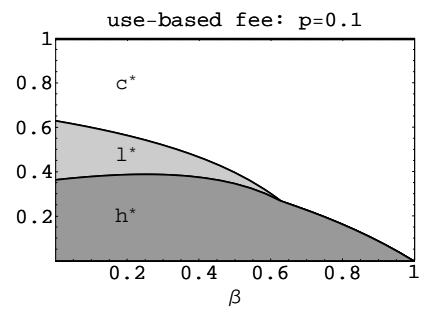

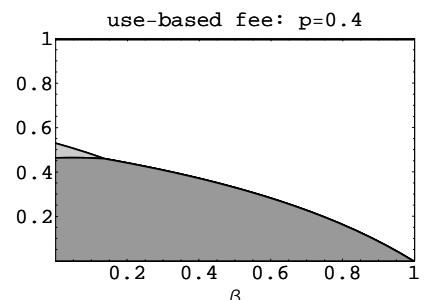

use-based fee: $p=0.7$

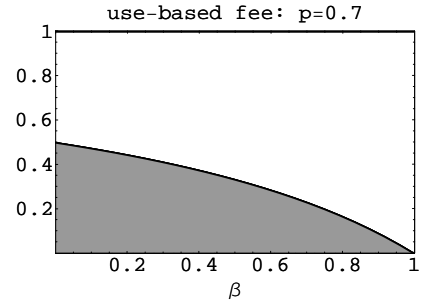

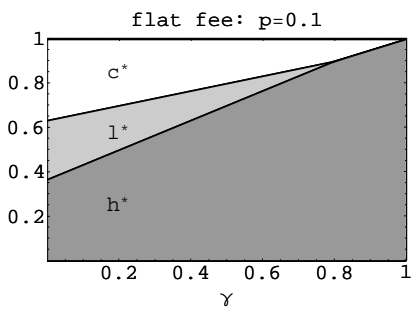

flat fee: $p=0.4$

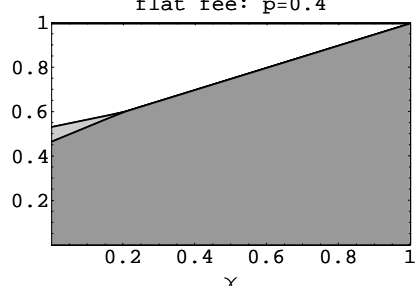

flat fee: $p=0.7$

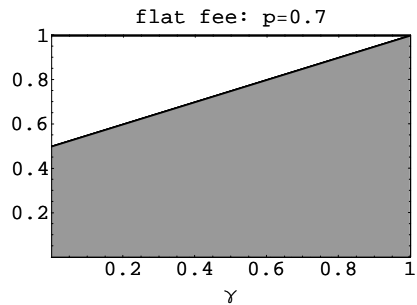

FiguRE 2. Optimal control over the fee parameter.

Under rather mild conditions parental behavior can be characterized as follows. ${ }^{4}$ The time path of both the demand for public child care and labor supply are increasing. However, with a longer education period, and hence with an extended time horizon, both time paths are shifted downwards, as the parent enhances at each instant of time his/her effort to promote the child's performance by spending more leisure time together with the child. In other words, while for a given education period parental labor supply increases as the child gets older, labor supply is negatively affected by an extension of this time period during which the child requires child care.

In order to derive policy conclusions, we investigate the implications of various public child care policies. In particular we consider three different fee schemes, levied upon the use of public child care services, as well as the efficiency level of public child care as policy instruments. The fee structures we deal with may be characterized as follows. Either the child care fee is proportional to income, or it is proportional to the duration the child is in public child care (fixed price per hour), or a flat fee is levied, that is, a fixed amount has to be paid whenever the child

\footnotetext{
${ }^{4}$ In order to derive clear-cut comparative static results for the optimal path of the child's performance level, however, we apply some more restrictive assumptions.
} 
is in public child care. In addition, we also scrutinize the impact of an exogenous change in the efficiency (or quality) of public child care services on labor-, leisure, child-care decisions. We find that these policies affect the parent's intertemporal behavior in notably different ways.

If the fee for public child care is proportional to income, a higher income 'tax rate', reducing the effective net wage, leads to a decrease in parental labor supply and thus in the demand for public child care. Under our assumptions, we conclude that a higher income tax rate shifts the optimal path of the child's achievement level upwards. In this sense a higher income-related fee is beneficial for the child but affects the labor market negatively.

If, as a second alternative, public child care is financed by a fee proportional to the consumption of public child care (use-based fee), an increase in this fee affects the demand for public child care negatively, while labor supply is positively affected for low but negatively for high fees. Hence, the compound substitution-income effect may work in either way. The resulting impact on the path of the child's performance, however, is beneficial, irrespective of the value of the fee. Although these conclusions are obtained under slightly more restrictive assumptions, we may conclude that a higher use-based fee and a higher income-based fee are comparable with regard to labor supply, child care demand, and the child's well-being, given that the use-based fee is sufficiently high.

If, however, the provision of public child care is financed by a fixed fee, a higher fee increases both the demand for public child care and parental labor supply. The path of the child's performance, however, is negatively affected, as the parent spends less time together with the child. Remarkably these effects are opposite to those obtained under an income-based fee system, reflecting the fact that under an income-related fee substitution effects dominate the parent's behavior, while under a fixed fee income effects dominate.

Finally, the effect of an improvement of public child care quality induces the parent to substitute leisure time spent together with the child by public care, enabling the parent to increase labor supply. This has, however, a negative effect on the child's performance. Remarkably, the effect of an improvement of the efficiency of public child care services is (apart from pure leisure time effects) similar to that of a higher fixed fee.

In order to complement our analysis, we also consider the possibility of corner solutions, namely of the possibility that leisure time spent without the child 
may drop to zero. - As our analysis shows, even though corner solutions may materialize, this does not affect our results substantially, however.

To summarize, we find that different fee systems may induce substantially diverging effects on labor supply, on the demand for public child care services, and on the child's ultimate performance (or education) level. In particular, a trade off between an encouragement of labor supply and an enhancement of the child's education level exists under almost all policy measures, except in the case of a small use-based fee. It is important for policy makers to deliberately take into account these consequences of possible policy measures. Either unexpected effects may come about or existing trade offs may rule out arriving at two desirable goals by means of one policy tool. 


\section{Appendix A.}

Problem (c.f. Seierstad and Sydsæter (1987, p. 275, p. 291, p. 390)). Let $\chi(t) \equiv\left(\chi_{1}(t), \ldots, \chi_{n}(t)\right) \in \mathbb{R}^{n}$ be an state vector and $\nu(t) \equiv\left(\nu_{1}(t), \ldots, \nu_{r}(t)\right) \in \mathbb{R}^{r}$ be an control vector. Consider the following problem,

$$
\max \int_{t_{0}}^{t_{1}} \zeta_{0}(\chi(t), \nu(t), t) d t+\Psi\left(\chi\left(t_{1}\right)\right), \quad\left(t_{0}, t_{1} \text { fixed }\right)
$$

subject to the vector differential equation and the initial condition

$$
\dot{\chi}(t)=\zeta(\chi(t), \nu(t), t), \quad \chi\left(t_{0}\right)=\chi^{0},\left(\chi^{0} \text { fixed }\right),
$$

the terminal conditions

$$
\chi_{i}\left(t_{1}\right) \geqslant \chi_{i}^{1}, \quad i=1, \ldots, n, \quad\left(\chi_{i}^{1} \text { all fixed }\right)
$$

and subject to the constraints

$$
\xi_{k}(\nu(t), t) \geqslant 0, \quad k=1, \ldots, s
$$

for all $t \in\left[t_{0}, t_{1}\right]$.

We assume that $\zeta_{i}(\chi, \nu, t), \partial \zeta_{i}(\chi, \nu, t) / \partial \chi_{j}$, and $\partial \zeta_{i}(\chi, \nu, t) / \partial \nu_{k}$ are continuous with respect to all the $n+r+1$ variables for $i=0,1, \ldots, n ; j=1, \ldots, n ; k=$ $1, \ldots, r, \xi_{k}(\nu(t), t)$ and $\partial \xi_{k}(\nu(t), t) / \partial \nu_{j}$ are continuous with respect to all the $r+1$ variables for $j=1, \ldots, r ; k=1, \ldots, s$, and $\Psi$ is a $C^{1}$-function. We call $(\chi(t), \nu(t))$ an admissible pair if $\nu(t)$ is piecewise continuous, $\chi(t)$ is continuous and piecewise continuously differentiable such that (A.2)-(A.4) are satisfied.

Let $\nu^{*}(t)$ be an optimal control and define the two sets $I_{t}^{-}$and $I_{t}^{+}$by

$$
\begin{aligned}
I_{t}^{-} & \equiv\left\{k \mid \xi_{k}\left(\nu^{*}\left(t^{-}\right), t\right)=0, k=1, \ldots, s\right\}, \\
I_{t}^{+} & \equiv\left\{k \mid \xi_{k}\left(\nu^{*}\left(t^{+}\right), t\right)=0, k=1, \ldots, s\right\},
\end{aligned}
$$

where $\nu^{*}\left(t^{-}\right)$denotes the left-hand limit of $\nu^{*}(t)$ at $t$ and $\nu^{*}\left(t^{+}\right)$is the corresponding right-hand limit. Then the constraint qualification is as follows: For every $t \in\left[t_{0}, t_{1}\right]$

(C1) If $I_{t}^{-} \neq \emptyset$, the matrix $\left\{\partial \xi_{k}\left(\nu^{*}\left(t^{-}\right), t\right) / \partial \nu_{i}\right\}, k \in I_{t}^{-}, i=1, \ldots, r$ has a rank equal to the number of elements in $I_{t}^{-}$.

(C2) If $I_{t}^{+} \neq \emptyset$, the matrix $\left\{\partial \xi_{k}\left(\nu^{*}\left(t^{+}\right), t\right) / \partial \nu_{i}\right\}, k \in I_{t}^{+}, i=1, \ldots, r$ has a rank equal to the number of elements in $I_{t}^{+}$.

(C3) If $t=t_{0}$, drop (C1), if $t=t_{1}$, $\operatorname{drop}(\mathrm{C} 2)$. 
Theorem 1 (The maximum principle (c. f. Seierstad and Sydsæter (1987, p. 276, p. 291, p. 396))). Let $\left(\chi^{*}(t), \nu^{*}(t)\right)$ be an admissible pair which solves problem (A.1)-(A.4). Assume that the constraint qualification (C1)-(C3) is satisfied. Then there exist numbers $\pi_{0}$ and $\rho_{1}, \ldots, \rho_{n}$, vector functions $\pi(t) \equiv\left(\pi_{1}(t), \ldots, \pi_{n}(t)\right)$ and $\mu(t) \equiv\left(\mu_{1}(t), \ldots, \mu_{s}(t)\right)$, where $\pi(t)$ is continuous and piecewise continuously differentiable and $\mu(t)$ piecewise continuous, such that for all $t \in\left[t_{0}, t_{1}\right]$ :

(I) $\left(\pi_{0}, \rho_{1}, \ldots, \rho_{n}\right) \neq(0,0, \ldots, 0)$.

(II) $H\left(\chi^{*}(t), \nu^{*}(t), \pi(t), t\right) \geqslant H\left(\chi^{*}(t), \nu, \pi(t), t\right)$ for all $\nu$ such that $\xi_{k}(\nu, t)>$ $0, k=1, \ldots, s$ where $H(\chi, \nu, \pi, t):=\pi_{0} \zeta_{0}(\chi, \nu, t)+\sum_{i=1}^{n} \pi_{i} \zeta_{i}(\chi, \nu, t)$.

(III) $\sum_{j=1}^{r}\left(\partial L^{*} / \partial \nu_{j}\right)\left(\nu_{j}-\nu_{j}^{*}(t)\right) \leqslant 0$ for all $\nu=\left(\nu_{1}, \ldots, \nu_{r}\right) \in \tilde{U}(t)$, where $L(\chi, \nu, \pi, \mu, t):=H+\sum_{k=1}^{s} \mu_{k} \xi_{k}(\nu, t), \partial L^{*} / \partial \nu_{j}$ means $\partial L / \partial \nu_{j}$ evaluated at $\left(\chi^{*}(t), \nu^{*}(t), \pi(t), \mu(t), t\right)$, and $\tilde{U}(t) \equiv\left\{\nu \mid \sum_{j=1}^{r}\left(\partial \xi_{k}^{*} / \partial \nu_{j}\right)\left(\nu_{j}-\nu_{j}^{*}(t)\right) \geqslant\right.$ 0 for all $\left.k, \xi_{k}\left(\nu^{*}(t), t\right)=0\right\}$.

(IV) $\mu_{k}(t) \geqslant 0\left(=0\right.$ if $\left.\xi_{k}\left(\nu^{*}(t), t\right)>0\right), k=1, \ldots, s$.

(V) $\dot{\pi}(t)=-\partial L^{*} / \partial \chi_{i}, i=1, \ldots, n$ except at points of discontinuity of $\nu^{*}(t)$, where $\partial L^{*} / \partial \chi_{i}$ means $\partial L / \partial \chi_{i}$ evaluated at $\left(\chi^{*}(t), \nu^{*}(t), \pi(t), \mu(t), t\right)$.

(VI) $\pi_{0}=0$ or $\pi_{0}=1$.

(VII) $\pi_{i}\left(t_{1}\right)=\pi_{0}\left(\partial \Psi\left(\chi^{*}\left(t_{1}\right)\right) / \partial \chi_{i}\right)+\sum_{k=1}^{n} \rho_{k}$ where $\rho_{k} \geqslant 0\left(=0\right.$ if $\left.\chi_{i}^{*}\left(t_{1}\right)>0\right)$, $i=1, \ldots, n$.

Theorem 2 (Filippov-Cesari (c. f. Seierstad and Sydsæter (1987, p. 285, p. 400))). Consider the problem (A.1)-(A.4). Assume that

(a) There exists an admissible pair $(\chi(t), \nu(t))$.

(b) The set $N(\chi, t) \equiv\left\{\left(\zeta_{0}(\chi, \nu, t)+\delta, \zeta(\chi, \nu, t)\right) \mid \delta \leqslant 0, \xi(\nu, t) \geqslant 0\right\}$ is convex for all $\chi$ and all $t \in\left[t_{0}, t_{1}\right]$.

(c) There exists a number $\kappa$ such that $\|\chi(t)\| \leqslant \kappa$ for all admissible pairs $(\chi(t), \nu(t))$, and all $t \in\left[t_{0}, t_{1}\right]$.

(d) There exists an open ball $B\left(0, \kappa_{1}\right) \equiv\left\{\theta \in \mathbb{R}^{r} \mid\|\theta\|<\kappa_{1}\right\}$ which, for all $\chi$ with $\|\chi\| \leqslant \kappa$ and all $t \in\left[t_{0}, t_{1}\right]$, contains the set $U(\chi, t) \equiv\{\nu \mid \xi(\nu, t) \geqslant 0\}$.

Then there exists an optimal pair $\left(\chi^{*}(t), \nu^{*}(t)\right)$ (where $\nu^{*}(t)$ is measurable).

Proof of Proposition 1. First, we argue that an optimal solution must lie in the interior of its admissible domain, viz. in the interior of $U \equiv\{(d, h) \mid 1 \geqslant d \geqslant$ $\left.0, d \geqslant h, h \geqslant\left(\beta d+\gamma \mathbf{1}_{d>0}\right) / \omega^{\alpha}\right\}$. The properties of the utility functions $u$ and $v$, formulated in (i) and (ii), namely $u^{\prime}(x) \rightarrow \infty$ as $x \rightarrow 0^{+}, v_{l}(l, c) \rightarrow \infty$ as $l \rightarrow 0^{+}$, and $v_{c}(l, c) \rightarrow \infty$ as $c \rightarrow 0^{+}$, exclude $x=0, l=0$, and $c=0$ being optimal. It 
follows that $d^{*}(t)=1$ cannot be optimal since $d^{*}(t)=1 \Rightarrow c^{*}(t)=0$; and $d^{*}(t)=0$ is ruled out since $d^{*}(t)=0 \Rightarrow c^{*}(t)=1 \Rightarrow l^{*}(t)=0$; also, $d^{*}(t)=h^{*}(t)$ is not optimal since $d^{*}(t)=h^{*}(t) \Rightarrow l^{*}(t)=0$; finally, $h^{*}(t)=\left(\beta d^{*}(t)+\gamma\right) / \omega^{\alpha}$ cannot be optimal since $h^{*}(t)=\left(\beta d^{*}(t)+\gamma\right) / \omega^{\alpha} \Rightarrow x^{*}(t)=0$. Hence an optimal control $\left(d^{*}(t), h^{*}(t)\right)$ belongs to the interior of $U$, that is, to $U^{\circ} \equiv\{(d, h) \mid 1>d>0, d>$ $\left.h, h>(\beta d+\gamma) / \omega^{\alpha}\right\}$.

Since $d^{*}(t)=0$ cannot be optimal, we simply drop the indicator function in the fee function, $\phi$. Economically, this implies that the parent were to pay the fixed fees $\alpha M(t)$ and $\gamma$ irrespective of whether or not public child care is used at all. The only effect of this modification is that it makes the sub-optimal choice $d(t)=0$ even more unattractive, and thus does not affect the optimal control, whatever it looks like.

With this pre-requisite, we now consider Theorem 1 (necessary conditions for optimality) for the control problem (6)-(11). Taking account of the form (A.4), we write $\xi_{1}:=1-d, \xi_{2}:=d, \xi_{3}:=d-h$, and $\xi_{4}:=h-(\beta d+\gamma) / \omega^{\alpha}$. Since $\left(d^{*}(t), h^{*}(t)\right) \in U^{\circ}$, it follows from (IV) that $\mu_{i}=0, i=1,2,3,4$. Then, define the 'current value' Hamiltonian by

$$
H(b, d, h, \pi):=\pi_{0}\left[u\left(\omega^{\alpha} h-\beta d-\gamma\right)+v(d-h, 1-d)+w(b)\right]+\pi f(1-d, q d) g(b) .
$$

We first show that $\pi_{0}=1$. By $b^{0}>0$, (iv), and (v), we have $b^{*}(t)>0$ for all $t \in[0, T]$. This implies, from (VII), $\rho_{1}=0$. Therefore, by (I) and (VI), $\pi_{0}=1$. Then (III) implies

$$
\begin{aligned}
& H_{d}^{*}=-\beta u^{\prime}+v_{l}-v_{c}+\pi\left(-f_{c}+q f_{y}\right) g=0, \\
& H_{h}^{*}=\omega^{\alpha} u^{\prime}-v_{l}=0 .
\end{aligned}
$$

This condition is sufficient for (II) if $H\left(b^{*}, d, h, \pi\right)=\pi_{0}\left[\hat{u}(d, h)+w\left(b^{*}\right)\right]+\pi \hat{f}(d) g\left(b^{*}\right)$ is concave in $(d, h)$, where $\hat{u}(d, h):=u\left(\omega^{\alpha} h-\beta d-\gamma\right)+v(d-h, 1-d)$ and $\hat{f}(d):=f(1-d, q d)$. We show that $H\left(b^{*}, d, h, \pi\right)$ is strictly concave in $(d, h)$. First, we obtain $\hat{u}_{d d}=\beta^{2} u^{\prime \prime}+v_{l l}-2 v_{l c}+v_{c c}, \hat{u}_{d h}=-\omega^{\alpha} \beta u^{\prime \prime}-v_{l l}+v_{l c}$, and $\hat{u}_{h h}=\omega^{\alpha 2} u^{\prime \prime}+v_{l l}$. By Assumptions (i) and (ii), we have $\hat{u}_{d d}<0, \hat{u}_{h h}<0$, and $\hat{u}_{d d} \hat{u}_{h h}-\left(\hat{u}_{d h}\right)^{2}=\left(\left(\omega^{\alpha}-\beta\right)^{2} v_{l l}+\omega^{\alpha}\left(\omega^{\alpha} v_{c c}-2 v_{l c}\left(\omega^{\alpha}-\beta\right)\right)\right) u^{\prime \prime}+v_{l l} v_{c c}-\left(v_{l c}\right)^{2}>0$, which shows that $\hat{u}$ is strictly concave. Second, we obtain $\hat{f}^{\prime \prime}=f_{c c}-2 q f_{c y}+q^{2} f_{y y}$. By Assumption (iv), $\hat{f}^{\prime \prime} \leqslant 0$, and thus $\hat{f}$ is concave. Last, with the above results, $\pi_{0}=1$, and $g\left(b^{*}\right)>0$, it remains to be shown that $\pi \geqslant 0 .{ }^{5}$ We claim that $\pi(t)>0$

\footnotetext{
${ }^{5} \mathrm{~A}$ nonnegative combination of concave functions is also concave.
} 
for all $t \in[0, T]$. Suppose that $\pi\left(t_{1}\right) \leqslant 0$ for some $t_{1}$. It follows from (VII) with $b^{*}(T)>0, \pi_{0}=1$, and (iii), that $\pi(T)>0$. Then, by continuity, there exists some $t_{2}$ such that $\pi\left(t_{2}\right)=0$ and $\dot{\pi}\left(t_{2}\right) \geqslant 0$. On the other hand, condition (V) can be written as

$$
\dot{\pi}=\left(r-f\left(1-d^{*}, q d^{*}\right) g^{\prime}\left(b^{*}\right)\right) \pi-w^{\prime}\left(b^{*}\right) .
$$

This equation yields $\dot{\pi}\left(t_{2}\right)=-w^{\prime}\left(b^{*}\left(t_{2}\right)\right)<0$, which is contradiction. Therefore $\pi(t)>0$ for all $t$, and we conclude that $H\left(b^{*}, d, h, \pi\right)$ is strictly concave in $(d, h)$.

Next, we show that the necessary conditions yield a unique candidate for $\left(b^{*}(t), d^{*}(t), h^{*}(t)\right)$. To this end, define $z(t) \equiv g(b(t)) \pi(t)$, and $H^{z}(b, d, h, z) \equiv$ $H(b, d, h, z / g(b))$. Then $z^{*}(t)=g\left(b^{*}(t)\right) \pi(t)>0$. By $\dot{z}^{*}=g^{\prime}\left(b^{*}\right) \dot{b}^{*} \pi+g\left(b^{*}\right) \dot{\pi}$ and eqs (7) and (A.10), we obtain $\dot{z}^{*}=r z^{*}-w^{\prime}\left(b^{*}\right) g\left(b^{*}\right)$. Then, by the assumption in Proposition 1, we have $\dot{z}^{*}=r z^{*}-C$. On the other hand, multiplying both sides of the condition $\pi(T)-\epsilon w^{\prime}\left(b^{*}(T)\right)=0$ by $g\left(b^{*}(T)\right)$ yields $z^{*}(T)-\epsilon w^{\prime}\left(b^{*}(T)\right) g\left(b^{*}(T)\right)=$ 0 . Again, by the assumption, we obtain $z^{*}(T)-\epsilon C=0$. The solution to $\dot{z}^{*}=$ $r z^{*}-C$ with $z^{*}(T)=\epsilon C$ is given by

$$
\tilde{z}^{*}(t)=\frac{C}{r}\left((r \epsilon-1) e^{-r(T-t)}+1\right) .
$$

Recall that $H\left(b^{*}, d, h, \pi\right)$, and thus $H^{z}\left(b^{*}, d, h, z^{*}\right)$ is strictly concave in $(d, h)$, and note that (A.8) and (A.9) can be written as

$$
\begin{aligned}
& H_{d}^{z *}=-\beta u^{\prime}+v_{l}-v_{c}+\left(-f_{c}+q f_{y}\right) z^{*}=0, \\
& H_{h}^{z *}=\omega^{\alpha} u^{\prime}-v_{l}=0 .
\end{aligned}
$$

Then, by the implicit function theorem, the above system has a unique solution $\left(d^{*}, h^{*}\right)=\left(d^{z}\left(z^{*}\right), h^{z}\left(z^{*}\right)\right)$. Substituting $z^{*}=\tilde{z}^{*}(t)$ into the solution, we get a control $\left(d^{*}(t), h^{*}(t)\right)=\left(d^{z}\left(\tilde{z}^{*}(t)\right), h^{z}\left(\tilde{z}^{*}(t)\right)\right)$. Then, by concavity of $g$ and the standard existence theorem, the solution to the initial value problem (7) and (9) with the control $d=d^{*}$ exists and, by the usual uniqueness theorem, is unique (see, e.g., Seierstad and Sydsæter (1987, Appendix A) for such theorems). We can now conclude that the necessary conditions provide a unique candidate for $\left(b^{*}(t), d^{*}(t), h^{*}(t)\right)$.

In order to show that this candidate is indeed optimal, we apply Theorem 2. We verify that the conditions (a)-(d) are satisfied: Set $(d(t), h(t)) \equiv(\bar{d}, \bar{h}) \in U^{\circ}$. The solution of the initial value problem (7) and (9) with $d=\bar{d}$ is denoted by $\bar{b}(t)$. The existence of $\bar{b}(t)$ is established by concavity of $g$ and the standard existence theorem for ordinary differential equations. From Assumptions (iv) and 
(v) together with $\bar{b}(t)>0$ it follows that an admissible triple $(\bar{b}(t), \bar{d}, \bar{h})$ exists. The set $N$ is given by $N(b, t)=\left\{\left(e^{-r t}(\hat{u}(d, h)+w(b))+\delta, \hat{f}(d) g(b)\right) \mid \delta \leqslant 0,(1-d, d, d-\right.$ $\left.\left.h, h-(\beta d+\gamma) / \omega^{\alpha}\right) \geqslant 0\right\}$. The concavity of $\hat{u}$ and $\hat{f}$ implies that the set $N(b, t)$ is convex for all $(b, t)$, which can be proved in the same way as in Seierstad and Sydsæter (1987, p. 134, Example 9)). The condition (c) follows from the concavity of $g$ and the standard existence theorem for ordinary differential equations. It is clear that $U(b, t)$ is bounded. We therefore conclude that, by Theorem 2, an optimal triple $\left(b^{*}(t), d^{*}(t), h^{*}(t)\right)$ exists. ${ }^{6}$ Hence, the unique candidate produced by the necessary conditions is optimal.

\section{APPENDix B.}

Proof of Proposition 2. We first consider the optimal control $\left(d^{*}(t), h^{*}(t)\right)$. To prove part (A), recall that $d^{*}(t)=d^{z}\left(\tilde{z}^{*}(t)\right)$ and $h^{*}(t)=h^{z}\left(\tilde{z}^{*}(t)\right)$, and then $\dot{d}^{*}=d^{z \prime}\left(\tilde{z}^{*}\right) \dot{\tilde{z}}^{*}$ and $\dot{h}^{*}=h^{z \prime}\left(\tilde{z}^{*}\right) \dot{\tilde{z}}^{*}$. First, by eq. (A.11), $\dot{\tilde{z}}^{*}=C(r \epsilon-1) e^{-r(T-t)}$. Second, applying the implicit function theorem to eqs (A.12) and (A.13), we obtain

$$
\left[\begin{array}{l}
d^{z \prime} \\
h^{z \prime}
\end{array}\right]=-\left(J^{*}\right)^{-1}\left[\begin{array}{c}
H_{d z}^{z *} \\
H_{h z}^{z *}
\end{array}\right]=-\left(J^{*}\right)^{-1}\left[\begin{array}{c}
-\left(f_{c}-q f_{y}\right) \\
0
\end{array}\right],
$$

where $\left(J^{*}\right)^{-1}$ is the inverse of the Jacobian matrix of $\left(H_{d}^{z}, H_{h}^{z}\right)$ evaluated along the optimal path, whose elements are all negative since $H_{d d}^{z *}=\hat{u}_{d d}+z^{*} \hat{f}^{\prime \prime}<0$, $H_{h h}^{z *}=\hat{u}_{h h}<0$, and $\left|J^{*}\right|=H_{d d}^{z *} H_{h h}^{z *}-\left(H_{d h}^{z *}\right)^{2}>0$ by strict concavity, and $H_{d h}^{z *}=$ $\hat{u}_{d h}=-\omega^{\alpha} \beta u^{\prime \prime}-v_{l l}+v_{l c}>0$ by Assumption (ii). Part (B) follows from eq. (B.1) and the fact that $\tilde{z}_{T}^{*}=-C(r \epsilon-1) e^{-r(T-t)}$.

We next consider the optimal control $\left(c^{*}(t), l^{*}(t)\right)$. The result for $c^{*}(t)$ is immediate from the above result together with $c^{*}(t)=1-d^{*}(t)$ for all $t$. For the result for $l^{*}(t)$ we use $l^{*}(t)=d^{*}(t)-h^{*}(t)$ for all $t$ implying $l^{*}(t)=\dot{d}^{*}(t)-\dot{h}^{*}(t)=$ $\left(d^{z \prime}\left(\tilde{z}^{*}\right)-h^{z \prime}\left(\tilde{z}^{*}\right)\right) \dot{\tilde{z}}^{*}$. Substituting from eq. (B.1) and using $\omega^{\alpha}>\beta$ and $v_{l c}=0$ yields the result.

Proof of Proposition 3. We first consider the optimal control $\left(d^{*}(t), h^{*}(t)\right)$. Using $d^{*}(t)=d^{z}\left(\tilde{z}^{*}(t)\right)$ and $h^{*}(t)=h^{z}\left(\tilde{z}^{*}(t)\right)$, both parts follow from eqs (A.11) and (B.1). We only show that eq. (A.11) implies $\tilde{z}_{r}^{*}=C\left[e^{-r(T-t)}(r(1-r \epsilon)(T-\right.$ $t)+1)-1] / r^{2}<0$ and $\tilde{z}_{\epsilon}^{*}=C r e^{-r(T-t)}>0$. The latter is clear. The former

\footnotetext{
${ }^{6} \mathrm{We}$ assume here that the optimal control is piecewise continuous. Regarding the risks of this assumption and the necessary changes if we allow the control only to be measurable, see Seierstad and Sydsæter (1987, p. 132-133, p. 276, p. 285).
} 
may be seen as follows. Let $p_{1}(r):=e^{r(T-t)}-1$ and $p_{2}(r):=r(1-r \epsilon)(T-t)$, Then, $\tilde{z}_{r}^{*}<0 \Leftrightarrow p_{1}(r)>p_{2}(r)$. It is immediate that $p_{1}(0)=p_{2}(0)=0$ and $p_{1}^{\prime}(0)=p_{2}^{\prime}(0)=T-t$. Finally, since $p_{1}^{\prime \prime}(r)>0$ and $p_{2}^{\prime \prime}(r)<0$, we conclude $p_{1}(r)>p_{2}(r)$.

We next consider the optimal control $\left(c^{*}(t), l^{*}(t)\right)$. The proof follows immediately from the above result together with the relations $c^{*}(t)=1-d^{*}(t)$ and $l^{*}(t)=d^{*}(t)-h^{*}(t)$ for all $t$.

\section{Appendix C.}

Proof of Proposition 4. We first consider the optimal control $\left(d^{*}(t), h^{*}(t)\right)$. Let $J^{*}$ be given as in the proof of Proposition 2, and let $J^{\alpha *}:=\left.J^{*}\right|_{\beta=0, \gamma=0}, J^{\beta *}:=$ $\left.J^{*}\right|_{\alpha=0, \gamma=0}$, and $J^{\gamma *}:=\left.J^{*}\right|_{\alpha=0, \beta=0}$. The results follow from an application of the implicit function theorem to eqs (A.12) and (A.13):

$$
\begin{aligned}
& {\left[\begin{array}{l}
d_{\alpha}^{*} \\
h_{\alpha}^{*}
\end{array}\right]_{\beta=0, \gamma=0}=-\left(J^{\alpha *}\right)^{-1}\left[\begin{array}{c}
H_{d \alpha}^{z *} \\
H_{h \alpha}^{z *}
\end{array}\right]_{\beta=0, \gamma=0}=-\left(J^{\alpha *}\right)^{-1}\left[\begin{array}{c}
0 \\
-\omega \omega^{\alpha} h^{*} u^{\prime \prime}-\omega u^{\prime}
\end{array}\right],} \\
& {\left[\begin{array}{l}
d_{\beta}^{*} \\
h_{\beta}^{*}
\end{array}\right]_{\alpha=0, \gamma=0}=-\left(J^{\beta *}\right)^{-1}\left[\begin{array}{c}
H_{d \beta}^{z *} \\
H_{h \beta}^{z *}
\end{array}\right]_{\alpha=0, \gamma=0}=-\left(J^{\beta *}\right)^{-1}\left[\begin{array}{c}
d^{*} \beta u^{\prime \prime}-u^{\prime} \\
-\omega d^{*} u^{\prime \prime}
\end{array}\right],} \\
& {\left[\begin{array}{l}
d_{\gamma}^{*} \\
h_{\gamma}^{*}
\end{array}\right]_{\alpha=0, \beta=0}=-\left(J^{\gamma *}\right)^{-1}\left[\begin{array}{c}
H_{d \gamma}^{* *} \\
H_{h \gamma}^{z *}
\end{array}\right]_{\alpha=0, \beta=0}=-\left(J^{\gamma *}\right)^{-1}\left[\begin{array}{c}
0 \\
-\omega u^{\prime \prime}
\end{array}\right],} \\
& {\left[\begin{array}{l}
d_{q}^{*} \\
h_{q}^{*}
\end{array}\right]=-\left(J^{*}\right)^{-1}\left[\begin{array}{c}
H_{d q}^{z *} \\
H_{h q}^{z *}
\end{array}\right]=-\left(J^{*}\right)^{-1}\left[\begin{array}{c}
z^{*} \hat{f}_{d q} \\
0
\end{array}\right],}
\end{aligned}
$$

where we treated $\alpha, \beta$ and $\gamma$ as additional arguments of all functions.

We next consider the optimal control $\left(c^{*}(t), l^{*}(t)\right)$. The proof follows immediately from the above result together with the relations $c^{*}(t)=1-d^{*}(t)$ and $l^{*}(t)=d^{*}(t)-h^{*}(t)$ for all $t$.

\section{APPENDIX D.}

Proof of Proposition 5. When $g(b):=A b^{\sigma}$, eq. (7) with $d=d^{*}$ is a Bernoulli-type equation: $\dot{b}^{*}=f\left(1-d^{*}, q d^{*}\right) A b^{* \sigma}$, whose solution for $b(0)=b^{0}$ is

$$
b^{*}(t)=b^{0} e^{\frac{A}{(1-\sigma)^{2}} \int_{0}^{t} f\left(1-d^{*}(s), q d^{*}(s)\right) d s} .
$$

This means that $b_{r}^{*} \gtreqless 0$ if $-\left(f_{c}-q f_{y}\right) d_{r}^{*} \gtreqless 0$, and $b_{\epsilon}^{*} \gtreqless 0$ if $-\left(f_{c}-q f_{y}\right) d_{\epsilon}^{*} \gtreqless 0$. From this, together with Proposition 3, (A) and (B) follow.

Proof of Proposition 6. Similar to the proof of Proposition 5. 


\section{ApPendix E.}

Proof of Proposition 7. We first prove part (A). We have $d^{*}=(\omega+$ $\left.\omega^{1 / \tau}\right) /\left(\omega+\omega^{1 / \tau}+\omega^{1 / \tau}(\omega-\beta)^{1-1 / \tau}\right)$ and $h^{*}=\left(\beta+\omega^{1 / \tau}\right) /\left(\omega+\omega^{1 / \tau}+\omega^{1 / \tau}(\omega-\beta)^{1-1 / \tau}\right)$.

Then it is straightforward to show that $d_{\beta}^{*}<0$, and $h_{\beta}^{*} \gtreqless 0 \Leftrightarrow\left(\omega^{1 / \tau}+(\omega-\right.$ $\left.\beta)^{1 / \tau}\right)\left(\omega+\omega^{1 / \tau}\right) \tau-\omega^{1 / \tau}\left(\omega^{1 / \tau}+\beta\right) \gtreqless 0$. Finally, $l_{\beta}^{*}<0$ and $c_{\beta}^{*}>0$ are easily verified from the relations $l^{*}(t)=d^{*}(t)-h^{*}(t)$ and $c^{*}(t)=1-d^{*}(t)$ for all $t$, respectively. Part (B) follows, together with $f_{c}-q f_{y}=0$, from the assertion $b_{\beta}^{*} \gtreqless 0$ if $-\left(f_{c}-q f_{y}\right) d_{\beta}^{*} \gtreqless 0$. See the proof of Proposition 5 .

\section{APPENDIX F.}

Proof of Proposition 8. The process establishing the existence of a unique optimal triple is similar to that in the proof of Proposition 1 and is therefore omitted. The only difference is that the restriction $d-h \geqslant 0$ can be active. First, let $\phi:=\phi^{\alpha}$. The optimal control, $l^{*}=d^{*}-h^{*}$, is given by $l^{*}=\max \left\{l^{\alpha}(\alpha, \tau, \omega, p), 0\right\}$ where $l^{\alpha}:=\left(1-p\left(1+((1-\alpha) \omega)^{-1+1 / \tau}\right)\right) /\left(2+((1-\alpha) \omega)^{-1+1 / \tau}\right)$. Then, it is immediate that $l_{p}^{\alpha}<0$. Moreover, it follows that $l^{\alpha} \gtreqless 0 \Leftrightarrow \alpha \gtreqless 1-(-1+1 / p)^{\tau /(1-\tau)} / \omega=$ : $\alpha^{c}(p)$, and then $\alpha^{c \prime}>0, \alpha^{c}\left(1 /\left(1+\omega^{-1+1 / \tau}\right)\right)=0$, and $\alpha^{c} \rightarrow 1$ as $p \rightarrow 1$. Second, let $\phi:=\phi^{\beta}$. The optimal control is given by $l^{*}=\max \left\{l^{\beta}(\beta, \tau, \omega, p), 0\right\}$ where $l^{\beta}:=\left(\omega-\beta-p \omega^{1 / \tau}\left(1+(\omega-\beta)^{1-1 / \tau}\right)\right) /\left(\omega+\omega^{1 / \tau}+\omega^{1 / \tau}(\omega-\beta)^{1-1 / \tau}\right)$. Then, it is clear that $l_{p}^{\beta}<0$. Moreover, it follows that $l^{\beta} \gtreqless 0 \Leftrightarrow \beta \leqq \beta^{c}(p)$ such that $\omega-\beta^{c}(p)-p \omega^{1 / \tau}\left(1+\left(\omega-\beta^{c}(p)\right)^{1-1 / \tau}\right)=0$, and then $\beta^{c \prime}<0, \beta^{c} \rightarrow \omega$ as $p \rightarrow 0^{+}$, and $\beta^{c}\left(1 /\left(1+\omega^{-1+1 / \tau}\right)\right)=0$. Last, let $\phi:=\phi^{\gamma}$. The optimal control is given by $l^{*}=\max \left\{l^{\gamma}(\gamma, \tau, \omega, p), 0\right\}$ where $l^{\gamma}:=\left(\omega-\gamma-p\left(\omega+\omega^{1 / \tau}\right)\right) /\left(2 \omega+\omega^{1 / \tau}\right)$. Then, it is obvious that $l_{p}^{\gamma}<0$. Moreover, it follows that $l^{\gamma} \gtreqless 0 \Leftrightarrow \gamma \lesseqgtr \omega-p\left(\omega+\omega^{1 / \tau}\right)=$ : $\gamma^{c}(p)$, and then $\gamma^{c \prime}<0, \gamma^{c} \rightarrow \omega$ as $p \rightarrow 0^{+}$, and $\gamma^{c}\left(1 /\left(1+\omega^{-1+1 / \tau}\right)\right)=0$. 


\section{REFERENCES}

S. L. Averett, H. E. Peters, and D. M. Waldman. Tax credits, labor supply, and child care. Review of Economics and Statistics, 79:125-135, 1997.

C. L. Baum. A dynamic analysis of the effect of child care costs on the work decisions of low-income mothers with infants. Demography, 39:139-164, 2002.

G. S. Becker and H. G. Lewis. On the interaction between the quantity and quality of children. Journal of Political Economy, 81:S279-S288, 1973.

G. S. Becker and N. Tomes. Child endowments and the quantity and quality of children. Journal of Political Economy, 84:S143-S162, 1976.

T. Bergstrom and S. Blomquist. The political economy of subsidized day care. European Journal of Political Economy, 12:443-457, 1996.

D. M. Blau and A. P. Hagy. The demand for quality in child care. Journal of Political Economy, 106:104-146, 1998.

D. M. Blau and P. K. Robins. Child-care costs and family labor supply. Review of Economics and Statistics, 70:374-381, 1988.

A. Brink and K. Nordblom. Child-care quality and fee structure: Effects on labor supply and leisure composition. Working Paper, No.157, Göteborg University, 2005.

R. Connelly. The effect of child care costs on married women's labor force participation. Review of Economics and Statistics, 74:83-90, 1992.

J. J. Heckman. Effects of child-care programs on women's work effort. Journal of Political Economy, 82:S136-S163, 1974.

M. Lundholm and H. Ohlsson. Wages, taxes and publicly provided day care. Journal of Population Economics, 11:185-204, 1998.

M. Lundholm and H. Ohlsson. Who takes care of the children? The quantityquality model revisited. Journal of Population Economics, 15:455-461, 2002.

C. Michalopoulos, P. K. Robins, and I. Garfinkel. A structural model of labor supply and child care demand. Journal of Human Resources, 27:166-203, 1992.

D. C. Ribar. Child care and the labor supply of married woman: Reduced form evidence. Journal of Human Resources, 27:134-165, 1992.

A. Seierstad and K. Sydsæter. Optimal Control Theory with Economic Applications. North-Holland, Amsterdam, 1987.

D. Xie. Increasing returns and increasing rates of growth. Journal of Political Economy, 99:429-435, 1991.

D. Xie. On time inconsistency: A technical issue in Stackelberg differential games. Journal of Economic Theory, 76:412-430, 1997. 


\title{
CESifo Working Paper Series
}

\author{
(for full list see www.cesifo-group.de)
}

1756 Richard Schmidtke, Private Provision of a Complementary Public Good, July 2006

1757 J. Atsu Amegashie, Intentions and Social Interactions, July 2006

1758 Alessandro Balestrino, Tax Avoidance, Endogenous Social Norms, and the Comparison Income Effect, July 2006

1759 Øystein Thøgersen, Intergenerational Risk Sharing by Means of Pay-as-you-go Programs - an Investigation of Alternative Mechanisms, July 2006

1760 Pascalis Raimondos-Møller and Alan D. Woodland, Steepest Ascent Tariff Reforms, July 2006

1761 Ronald MacDonald and Cezary Wojcik, Catching-up, Inflation Differentials and Credit Booms in a Heterogeneous Monetary Union: Some Implications for EMU and new EU Member States, July 2006

1762 Robert Dur, Status-Seeking in Criminal Subcultures and the Double Dividend of ZeroTolerance, July 2006

1763 Christa Hainz, Business Groups in Emerging Markets - Financial Control and Sequential Investment, July 2006

1764 Didier Laussel and Raymond Riezman, Fixed Transport Costs and International Trade, July 2006

1765 Rafael Lalive, How do Extended Benefits Affect Unemployment Duration? A Regression Discontinuity Approach, July 2006

1766 Eric Hillebrand, Gunther Schnabl and Yasemin Ulu, Japanese Foreign Exchange Intervention and the Yen/Dollar Exchange Rate: A Simultaneous Equations Approach Using Realized Volatility, July 2006

1767 Carsten Hefeker, EMU Enlargement, Policy Uncertainty and Economic Reforms, July 2006

1768 Giovanni Facchini and Anna Maria Mayda, Individual Attitudes towards Immigrants: Welfare-State Determinants across Countries, July 2006

1769 Maarten Bosker and Harry Garretsen, Geography Rules Too! Economic Development and the Geography of Institutions, July 2006

1770 M. Hashem Pesaran and Allan Timmermann, Testing Dependence among Serially Correlated Multi-category Variables, July 2006 
1771 Juergen von Hagen and Haiping Zhang, Financial Liberalization in a Small Open Economy, August 2006

1772 Alessandro Cigno, Is there a Social Security Tax Wedge?, August 2006

1773 Peter Egger, Simon Loretz, Michael Pfaffermayr and Hannes Winner, Corporate Taxation and Multinational Activity, August 2006

1774 Jeremy S.S. Edwards, Wolfgang Eggert and Alfons J. Weichenrieder, The Measurement of Firm Ownership and its Effect on Managerial Pay, August 2006

1775 Scott Alan Carson and Thomas N. Maloney, Living Standards in Black and White: Evidence from the Heights of Ohio Prison Inmates, 1829 - 1913, August 2006

1776 Richard Schmidtke, Two-Sided Markets with Pecuniary and Participation Externalities, August 2006

1777 Ben J. Heijdra and Jenny E. Ligthart, The Transitional Dynamics of Fiscal Policy in Small Open Economies, August 2006

1778 Jay Pil Choi, How Reasonable is the 'Reasonable’ Royalty Rate? Damage Rules and Probabilistic Intellectual Property Rights, August 2006

1779 Ludger Woessmann, Efficiency and Equity of European Education and Training Policies, August 2006

1780 Gregory Ponthiere, Growth, Longevity and Public Policy, August 2006

1781 Laszlo Goerke, Corporate and Personal Income Tax Declarations, August 2006

1782 Florian Englmaier, Pablo Guillén, Loreto Llorente, Sander Onderstal and Rupert Sausgruber, The Chopstick Auction: A Study of the Exposure Problem in Multi-Unit Auctions, August 2006

1783 Adam S. Posen and Daniel Popov Gould, Has EMU had any Impact on the Degree of Wage Restraint?, August 2006

1784 Paolo M. Panteghini, A Simple Explanation for the Unfavorable Tax Treatment of Investment Costs, August 2006

1785 Alan J. Auerbach, Why have Corporate Tax Revenues Declined? Another Look, August 2006

1786 Hideshi Itoh and Hodaka Morita, Formal Contracts, Relational Contracts, and the Holdup Problem, August 2006

1787 Rafael Lalive and Alejandra Cattaneo, Social Interactions and Schooling Decisions, August 2006 
1788 George Kapetanios, M. Hashem Pesaran and Takashi Yamagata, Panels with Nonstationary Multifactor Error Structures, August 2006

1789 Torben M. Andersen, Increasing Longevity and Social Security Reforms, August 2006

1790 John Whalley, Recent Regional Agreements: Why so many, why so much Variance in Form, why Coming so fast, and where are they Headed?, August 2006

1791 Sebastian G. Kessing and Kai A. Konrad, Time Consistency and Bureaucratic Budget Competition, August 2006

1792 Bertil Holmlund, Qian Liu and Oskar Nordström Skans, Mind the Gap? Estimating the Effects of Postponing Higher Education, August 2006

1793 Peter Birch Sørensen, Can Capital Income Taxes Survive? And Should They?, August 2006

1794 Michael Kosfeld, Akira Okada and Arno Riedl, Institution Formation in Public Goods Games, September 2006

1795 Marcel Gérard, Reforming the Taxation of Multijurisdictional Enterprises in Europe, a Tentative Appraisal, September 2006

1796 Louis Eeckhoudt, Béatrice Rey and Harris Schlesinger, A Good Sign for Multivariate Risk Taking, September 2006

1797 Dominique M. Gross and Nicolas Schmitt, Why do Low- and High-Skill Workers Migrate? Flow Evidence from France, September 2006

1798 Dan Bernhardt, Stefan Krasa and Mattias Polborn, Political Polarization and the Electoral Effects of Media Bias, September 2006

1799 Pierre Pestieau and Motohiro Sato, Estate Taxation with Both Accidental and Planned Bequests, September 2006

1800 Øystein Foros and Hans Jarle Kind, Do Slotting Allowances Harm Retail Competition?, September 2006

1801 Tobias Lindhe and Jan Södersten, The Equity Trap, the Cost of Capital and the Firm's Growth Path, September 2006

1802 Wolfgang Buchholz, Richard Cornes and Wolfgang Peters, Existence, Uniqueness and Some Comparative Statics for Ratio- and Lindahl Equilibria: New Wine in Old Bottles, September 2006

1803 Jan Schnellenbach, Lars P. Feld and Christoph Schaltegger, The Impact of Referendums on the Centralisation of Public Goods Provision: A Political Economy Approach, September 2006 
1804 David-Jan Jansen and Jakob de Haan, Does ECB Communication Help in Predicting its Interest Rate Decisions?, September 2006

1805 Jerome L. Stein, United States Current Account Deficits: A Stochastic Optimal Control Analysis, September 2006

1806 Friedrich Schneider, Shadow Economies and Corruption all over the World: What do we really Know?, September 2006

1807 Joerg Lingens and Klaus Waelde, Pareto-Improving Unemployment Policies, September 2006

1808 Axel Dreher, Jan-Egbert Sturm and James Raymond Vreeland, Does Membership on the UN Security Council Influence IMF Decisions? Evidence from Panel Data, September 2006

1809 Prabir De, Regional Trade in Northeast Asia: Why do Trade Costs Matter?, September 2006

1810 Antonis Adam and Thomas Moutos, A Politico-Economic Analysis of Minimum Wages and Wage Subsidies, September 2006

1811 Guglielmo Maria Caporale and Christoph Hanck, Cointegration Tests of PPP: Do they also Exhibit Erratic Behaviour?, September 2006

1812 Robert S. Chirinko and Hisham Foad, Noise vs. News in Equity Returns, September 2006

1813 Oliver Huelsewig, Eric Mayer and Timo Wollmershaeuser, Bank Behavior and the Cost Channel of Monetary Transmission, September 2006

1814 Michael S. Michael, Are Migration Policies that Induce Skilled (Unskilled) Migration Beneficial (Harmful) for the Host Country?, September 2006

1815 Eytan Sheshinski, Optimum Commodity Taxation in Pooling Equilibria, October 2006

1816 Gottfried Haber and Reinhard Neck, Sustainability of Austrian Public Debt: A Political Economy Perspective, October 2006

1817 Thiess Buettner, Michael Overesch, Ulrich Schreiber and Georg Wamser, The Impact of Thin-Capitalization Rules on Multinationals' Financing and Investment Decisions, October 2006

1818 Eric O’N. Fisher and Sharon L. May, Relativity in Trade Theory: Towards a Solution to the Mystery of Missing Trade, October 2006

1819 Junichi Minagawa and Thorsten Upmann, Labor Supply and the Demand for Child Care: An Intertemporal Approach, October 2006 